\title{
UČINKOVITOST MCKENZIE KONCEPTA I STANDARDNE KINEZITERAPIJE NA SMANJENJE BOLI KOD KRONIČNE VERTEBRALNE KRIŽOBOLJE
}

\author{
Antonija Hrkać, Lejla Obradović - Salčin, Vesna Miljanović - Damjanović \\ Fakultet zdravstvenih studija Mostar \\ Rad je primljen 26.10.2015. \\ Rad je korigiran 12.04.2016. \\ Rad je prihvaćen 24.04.2016.
}

\section{SAŽETAK}

UVOD: Fizikalna terapija u liječenju kroničnih križobolja zauzima vodeće mjesto. Primjenjuju se različite metode fizikalne terapije, ali za sada, jedino kineziterapija ima dokazanu učinkovitost. Iz tog razloga u području kineziterapije došlo je do razvoja različitih koncepta i metoda za liječenje bolesti kralježnice. Učinkovitost tih koncepata i metoda u odnosu na standardne kineziterapijske metode još uvijek nema znanstvenu potvrdu. Prema izboru stručnjaka, McKenzie koncept zauzima vodeće mjesto u izboru liječenja križobolja.

CILJ: Usporediti učinkovitost McKenzie koncepta i standardne kineziterapije na smanjenje boli kod kronične vertebralne križobolje te usporediti koja od ovih dviju metoda je učinkovitija u liječenju kronične vetrebralne križobolje.

ISPITANICI I METODE: Uključena su 72 ispitanika, oba spola od 30.-50. godine života s kroničnom vertebralnom križoboljom koji su liječeni na Klinici za Fizikalnu medicinu i rehabilitaciju SKB Mostar. Glavna mjera istraživanja je bol, mjerena VAS ljestvicom. U istraživanje su uključeni ispitanici koji su na prvom mjerenju imali ocjenu 6 na VAS ljestvici. Ispitanici su slučajnim odabirom podijeljeni na ispitnu i kontrolnu skupinu koje su se razlikovale prema metodi kineziterapije primijenjene u liječenju. Evaluacija je provedena neposredno prije tretmana i nakon tretmana koji je trajao 14 dana. REZULTATI: Skupine su imale po 36 ispitanika. Ženski spol je bio zastupljeniji u obje skupine. Na početku istraživanja skupine se nisu razlikovale po dobi, spolu i razini boli. Nakon 14 dana ponovljena je procjena boli u obje skupine. Poboljšanje u procjeni boli statistički je značajno u kontrolnoj skupini u kojoj se provodila standardna kineziterapija $(\mathrm{z}=-3,197$; $\mathrm{p}=0,0014)$ kao i ispitnoj skupini u kojoj se provodio McKenzie koncept $(\mathrm{z}=-4,007 ; \mathrm{p}=0,0001)$. Nije bilo statistički značajnih razlika između skupina u smanjenju boli $(\mathrm{t}=1,54 ; \mathrm{p}=0,063)$.

ZAKLJUČAK: McKenzie i standardne vježbe u kineziterapiji djeluju učinkovito na smanjenje boli u kratkom periodu tretmana. McKenzie koncept nije učinkovitiji od standardne kineziterapije na smanjenje boli kod kronične vertebralne križobolje.

Ključne riječi: križobolja, kronična, kineziterapija, McKenzie

Osoba za razmjenu informacija:

Antonija Hrkać

antonija.hr@gmail.com

\section{UVOD}

Lumbalni bolni sindrom ili križobolju opisujemo kao pojavu boli, napetosti mišića i smanjenu funkcionalnu pokretljivost lumbalnog dijela kralježnice, pri kojem simptom boli može biti lokaliziran u lumbalnom dijelu kralježnice (vertebralni sindrom) ili se može širiti duž noge zbog uključenosti korjenova spinalnih živaca (vertebrogeni sindrom). Prema duljini trajanja simptoma razlikujemo: akutni oblik križobolje (simptomi prisutni do 6 tjedana), subakutni (simptomi prisutni od 6 do 12 tjedana) i kronični oblik (simptomi prisutni duže od 12 tjedana). Najčešća dob nastanka križobolje je između 30. i 50. godine života, ali se može pojaviti u svakoj dobnoj skupini.

Procjenjuje se da 50 do $80 \%$ populacije osjeti križobolju barem jednom tijekom svog života (4). U studiji koja je istraživala pojavnost križobolje kod mlađe dobne skupine, a koju su proveli Kovacs i suradnici, nalazimo podatke da je 11 do $50 \%$ adolescenata u dobi između 11 i 15 godine izjavilo da je imalo epizodu križobolje (2). Kronični tijek 
križobolje predstavlja glavni socioekonomski problem gdje $5 \%$ bolesnika proizvede $75 \%$ svih ukupnih troškova liječenja križobolja (1).

Čimbenici rizika za pojavu i razvoj križobolje su brojni i raznoliki. Među glavnim uzrokom ili razlogom pojave križobolje, kao posljedicom djelovanja čimbenika rizika ili procesa starenja organizma, nalaze se promjene u vertebralnom dinamičkom segmentu kralježnice (VDS).

Fizioterapija ima važnu ulogu u liječenju križobolja. U liječenju križobolja od metoda fizikalne terapije koriste se: elektroterapija (magnetoterapija, galvanizacija, dijadinamske struje, interferentne struje, transkutana električna živčana stimulacija, kratkovalna i mikrovalna dijatermija), toplinska terapija, ultrazvuk, svjetlosna terapija, masaža, akupunktura i akupresura, trakcija, kineziterapija ili medicinska gimnastika, manualna terapija te edukacija bolesnika o pravilnim, zaštitnim položajima i pokretima.

U terapiji kronične križobolje kineziterapija kao klinički i znanstveno dokazana metoda nalazi se na prvom mjestu u izboru liječenja (4). Danas u kineziterapiji, pored „standardne“ kineziterapije, bilježimo razvoj brojnih koncepata i metoda kineziterapije za bolna McKenzie koncept, prema izboru stručnjaka, danas je najčešće primjenjivana kineziterapijska metoda u terapiji križobolje, ali i ostalih bolesti kralježnice (1).

\section{CILJ}

Usporediti učinkovitost McKenzie koncepta i standardne kineziterapije na smanjenje boli kod kronične vertebralne križobolje te usporediti koja od ovih dviju metoda je učinkovitija u liječenju kronične vetrebralne križobolje.

\section{ISPITANICI I METODE}

Istraživanje je provedeno na Klinici za fizikalnu medicinu i rehabilitaciju Sveučilišne kliničke bolnice (SKB) Mostar. Ustroj istraživanja je prospektivno istraživanje.

$\mathrm{U}$ istraživanje su uključeni bolesnici s dijagnosticiranom kroničnom vertebralnom križoboljom (dijagnoza je postavljena od strane liječnika radiologa i fizijatra) koji su liječeni na Klinici za fizikalnu medicinu i rehabilitaciju SKB Mostar u periodu od 1. siječnja 2014. do 31. srpnja 2014. godine. U istraživanje su uključena 72 bolesnika oba spola, dobi od 30. do 50. godine života. U studiji je sudjelovalo 29 muškaraca i 43 žene. Svi ispitanici uključeni u istraživanje imali su ocjenu 6 na VAS ljestvici jer je to bio kriterij uključenja u istraživanje.

Kriteriji isključenja iz istraživanja su bili: sve ostale križobolje osim gore navedene (nespecifična ili degenerativna), bolesnici s psihičkim poremećajima, neredovitost dolaska na tretmane, nedostatak suradnje između pacijenta i terapeuta, trudnice te drugi zdravstveni problemi bolesnika (bolesti genitourinarnog trakta, teške kardiovaskularne i respiratorne bolesti, maligni, benigni i metastatski tumori, prirođene anomalije kralježnice, traume kralježnice te infektivne i metaboličke bolesti). Isključenja iz istraživanja nije bilo.

Ispitanici uključeni u istraživanje potpisali su informirani pristanak. Osobni podatci (ime i prezime) dobiveni tijekom istraživanja od ispitanika anonimni su za javnost. Svi prijavljeni ispitanici u ovom istraživanju su sudjelovali do kraja studije.

$\mathrm{Na}$ početku istraživanja ispitanici su podijeljeni na ispitnu i kontrolnu skupinu postupkom randomizacije (dodjela nasumičnih brojeva) upotrebom elektroničkog generatora nasumičnih brojeva koji se nalazi na mrežnoj stranici www.randomizer.org/ form:htm.

Glavna mjera ishoda istraživanja je procjena boli, mjerena Vizualnom analognom ljestvicom (8). Ispitna i kontrolna skupina razlikovale su se prema vrsti provedene kineziterapije, a zajednička im je edukacija o pravilnim položajima i pokretima. U ispitnoj skupini bolesnici su imali program kineziterapije po McKenzie konceptu u trajanju od $30 \mathrm{mi}-$ nuta i edukaciju o pravilnim položajima i pokretima u trajanju od 45 minuta, dok je kontrolna skupina provodila standardnu kineziterapiju za bolna križa u trajanu od 30 minuta i edukaciju o pravilnim položajima i pokretima u trajanju od 45 minuta. Standardna kineziterapija sastojala se od vježbi istezanja i zagrijavanja, vježbi opsega pokreta, vježbi snaženja mišića trupa, vježbi balansa i koordinacije te vježbi disanja i relaksacije. McKenzie koncept proveo se po 
svojim načelima koja se sastoje od procjene i individualno odabranih ekstenzijskih vježbi. Edukacija bolesnika u obje skupine sastojala se od savjetovanja i praktičnih primjera pravilnih položaja i pokreta tijela. Bolesnici su naučeni kako pravilno stajati, hodati, podizati teret, saginjati se, provoditi transfere iz ležećeg i sjedećeg položaja. Tretman u obje skupine provodio se svakodnevno kroz 14 dana. Ispitanici su savjetovani za izvođenje naučenih vježbi, pravilnih položaja i pokreta kod kuće. Procjena boli provedena je prije provedbe tretmana i nakon 14 dana, nakon provedenih tretmana.

Prikupljeni podatci obrađeni su metodom deskriptivne statistike. Statistička značajnost testirana je Nezavisnim t-testom i Wilcoxonovim testom. Razina značajnosti je bila $\mathrm{p}<0,05$, osim za Wilcoxonov test gdje je razina značajnosti $\mathrm{p} \leq 0,05$. Za prikaz distribucije podataka korišten je D'Agostino-Pearsonov test. Za statističku analizu podataka koristili su se programski sustavi SPSS for Windows (inačica 19, IBM, SAD), MedCalc (version 14. 12.0) i Microsoft Excell 2007.

\section{REZULTATI}

Prije provedbe tretmana kineziterapije dvije skupine nisu se razlikovale po broju ispitanika $(\mathrm{n}=36)$ i dobi ispitanika $(t=-1.89 ; \mathrm{p}=0.062)$. Nije bilo razlika između skupina u procjeni boli prije početka provedbe istraživanja iz razloga što je u obje skupine ocjena na VAS ljestvici bila 6, a što je bio kriterij uključenja u istraživanje. Ocjena 6 prema interpretaciji mjerne ljestvice označavala je da su svi ispitanici na razini osjeta umjerene boli. U kontrolnoj skupini varijabla dob slijedila je normalnu raspodjelu podataka ( $\mathrm{p}=0,2753)$, kao i u ispitnoj $(\mathrm{p}=0,0693)$. U kontrolnoj skupini je bilo više žena (58 \%) u odnosu na muškarce (42\%), u ispitnoj skupini bilo je isto više žena (61 \%) u odnosu na muškarce (39 \%). Nakon 14 dana tretmana u obje skupine provedena je ponovljena procjena boli VAS ljestvicom. Nije bilo isključivanja iz istraživanja na ponovljenoj procjeni. Razina osjeta boli ispitanika nakon provedene kineziterapije u obje skupine je promijenjena (tablica 1 ).
Tablica 1. Razina boli u ispitanika nakon provedenog tretmana

\begin{tabular}{lcccccccc}
\hline & \multicolumn{3}{c}{ Standardna kineziterapija } & \multicolumn{3}{c}{ Mckenzie koncept } \\
\cline { 2 - 9 } & \multicolumn{2}{c}{ VAS1 } & \multicolumn{2}{c}{ VAS2 } & \multicolumn{3}{c}{ VAS1 } & \multicolumn{2}{c}{ VAS2 } \\
\hline & $\mathrm{N}$ & $\%$ & $\mathrm{~N}$ & $\%$ & $\mathrm{~N}$ & $\%$ & $\mathrm{~N}$ & $\%$ \\
Blaga bol & & & 7 & 20 & & & 19 & 53 \\
Umjerena bol & \multirow{2}{*}{36} & \multirow{2}{*}{100} & 24 & 66 & 36 & 100 & 14 & 39 \\
Jaka bol & & & 5 & 14 & & & 3 & 8 \\
\hline
\end{tabular}

Prosječna ocjena u kontrolnoj skupini na ponovljenoj procjeni boli (VAS 2) je 5,1 $\pm 1,1$, a u ispitnoj skupini $4,7 \pm 1,2$, što u obje skupine pokazuje manju ocjenu, odnosno smanjenu razinu boli u odnosu na početno mjerenje.

U kontrolnoj skupini u kojoj je provedena standardna kineziterapija rezultati ocjena VAS ljestvice su sljedeći: ocjenu 3 označilo je $6 \%$ ispitanika, ocjenu 4 označilo je $13 \%$ ispitanika, ocjenu 5 označilo je $61 \%$ ispitanika, ocjenu 6 označilo je $6 \%$ ispitanika, ocjenu 7 označilo je $6 \%$ ispitanika i ocjenu 8 označilo je $8 \%$ ispitanika. U ispitnoj skupini ocjenu 3 označilo je $9 \%$ ispitanika, ocjenu 4 označilo je $42 \%$ ispitanika, ocjenu 5 označilo je $25 \%$ ispitanika, ocjenu 6 označilo je $15 \%$ ispitanika, ocjenu 7 označilo je $3 \%$ ispitanika i ocjenu 8 označilo je $6 \%$ ispitanika (slika 2).

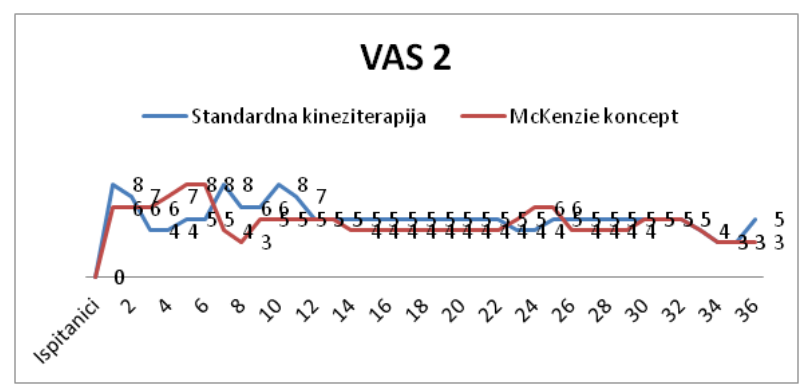

Slika 2. Rezultati mjerenja ponovljene procjene razine boli (VAS 2) ispitanika nakon provedenog tretmana

Distribucija podataka u ponovljenoj procjeni boli nije prihvaćena kao normalna u kontrolnoj skupini $(\mathrm{p}=0,0161)$, kao ni u ispitnoj skupini $(\mathrm{p}=0,0214)$.

Kako bi utvrdili učinkovitost McKenzie koncepta i standardne kineziterapije na smanjenje boli u liječenju kroničnih vertebralnih križobolja, usporedili smo rezultate početne i ponovljene procjene. Rezultati statističkog testa pokazuju da McKenzie koncept učinkovito djeluje na smanjenje boli $(\mathrm{z}=-4,007 ; \mathrm{p}=$ $0,0001)$ kao i standardna kineziterapija $(\mathrm{z}=-3,197$; $\mathrm{p}=0,0014)$. 
Medutim, statističkom testom je utvrđeno da McKenzie koncept nije učinkovitiji od standardnih kineziterapijskih metoda u liječenju kroničnih vertebralnih križobolja $(t=1,54 ; \mathrm{p}=0,063)$.

\section{RASPRAVA}

McKenzie koncept je danas u svijetu najraširenija i najčešće primjenjivana metoda kineziterapije za liječenje križobolja. Unatoč svojoj širokoj primjeni, primjena McKenzie koncepta u liječenju kronične križobolje, ali i ostalih bolesti kralježnice, još uvijek nije utemeljena na dokazima. U odnosu na druge metode kineziterapije McKenzie koncept je učinkovitiji u ranom stadiju liječenja ( $<3$ mjeseca), a što je u skladu s ovim provedenim istraživanjem $(3,7)$. U sustavnom pregledu iz 2006. godine prikazana je pozitivna učinkovitost ovog tretmana u akutnoj križobolji kod $74 \%$ ispitanika, subakutnoj kod $50 \%$, a u kroničnoj kod $40 \%$ ispitanika. Ovaj koncept učinkovitiji je u mlađih bolesnika (6). Kineziterapija koja se sastoji od individualno prilagođenog programa vježbi, uključujući istezanje i jačanje mišića te koji se odvija pod vodstvom supervizora, a što je sve sastavni dio McKenzie koncepta, djeluje na smanjenje boli i poboljšanju kvalitete života bolesnika koji pate od kronične križobolje (9).

Zagovornici McKenzie koncepta smatraju da ovaj oblik kineziterapije mogu provoditi samo posebno educirani McKenzie terapeuti, po strogim McKenzie protokolima kako bi se McKenzie koncept pokazao uspješniji od ostalih metoda kineziterapije $(5,8,9,12)$. Međutim, na prostoru Hercegovine još uvijek nema posebno educiranih terapeuta za McKenzie koncept, kako bi se ovaj oblik kineziterapije provodio strogo po njegovim načelima koja se sastoje od procjene, individualno odabranog seta vježbi za svakog ispitanika te opsežne edukacije za svakodnevan život.

S druge strane, istraživanja provedena kako bi se utvrdilo koji oblik kineziterapije najučinkovitije smanjuje bol te poboljšava funkcionalni status ispitanika koji pate od križobolje nisu izdvojila ni jednu metodu kineziterapije kao superiorniju, odnosno učinkovitiju. Bilo koja metoda kineziterapije je djelotvorna na smanjenje kronične boli u radno aktivne populacije, a što se isto može potvrditi i s ovim provedenim istraživanjem (11-13).

Odluka koju metodu kineziterapije primjenjivati u liječenju kronične križobolje ostaje na stručnjacima koji se bave ovim bolnim stanjem. Iz tog razloga od velike je važnosti stalna i kontinuirana edukacija fizioterapeuta kako bi što bolje i učinkovitije sudjelovali u liječenju i oporavku bolnih sindroma, proučavali učinkovitost različitih metoda fizikalne terapije te tako u svojoj struci pridonijeli razvoju medicine temeljene na dokazima.

\section{ZAKLJUČAK}

McKenzie i standardne vježbe u kineziterapiji djeluju učinkovito na smanjenje boli u liječenju kronične vertebralne križobolje. McKenzie koncept nije učinkovitiji od standardne kineziterapije na smanjenje boli kod kronične vertebralne križobolje. Preporučuje se ponavljanje istraživanja koje bi trajalo duže vremensko razdoblje od ovog provedenog $(<3$ mjeseca).

\section{LITERATURA}

1. Airaksinen O, Brox JI, Cedraschi C, Hildebrandt J, Klaber-Moffett J, Kovacs F, i sur. European guidelines for the managment of chronic nonspecific low back pain. Eur Spine J. 2006;15:192-300.

2. Kovacs FM, Gestoso M, Gill Del Real MT, Lopez J, Mufraggi N, Mendez JI. Risk factors for non - specific low back pain in schoolchildren and their parents: A population based study. Pain. 2003;103:259-68.

3. Busanich Bm, Verscheure SD. Does McKenzie Therapy Improve Outcomes for Back Pain. J Athl Train. 2006;41:117-19.

4. Wheeler A. Diagnosis and management of low back pain and sciatica. Am Fam Physician. 1995;52:1333-41.

5. Clare HA, Adams R, Maher CG. A systematic review of efficacy of McKenzie therapy for spinal pain. Aust J Physiother. 2004;50:209-16.

6. May S, Donelson R. Evidence-informed management of chronic low back pain with the McKenzie method Spine J. 2008;8:134-41. 
7. Machado LAC, von Sperling de Souza M, Ferreira PH, Ferreira ML. The McKenzie method for low back pain: A systematic review of the literature with a meta-analysis approach. Spine. 2006;31:258-62.

8. Childs JD, Piva SR, Fritz JM. Responsiveness of the numeric pain rating scale in patients with low back pain. Spine. 2005;30:1331-34.

9. Busanich BM, Verscheure SD. Does McKenzie therapy improve outcomes for back pain. J Athl Train. 2006;41:117-19.

10. May S, Aina A. Centralization and directional preference: A systematic review. Manual Therapy. 2012;17:497-506.
11. Dreisinger TE. Exercise in the management of chronic back pain. Ochsner J. 2014;14:101-107.

12. Hayden JA, van Tulder MW, Tomlinson G. Systematic review: strategies for using exercise therapy to improve outcomes in chronic low back pain. Ann Intern Med. 2005;142:776-85.

13. Van Tulder, Koes BW, Bouter LM. Conservative treatment of acute and chronic nonspecific low back pain: A systematic review of randomized controlled trials of the most common interventions Spine. 1997;22:2128-56. 


\title{
EFFICIENCY MCKENZIE CONCEPT AND STANDARD KINESITHERAPY TO REDUCE PAIN IN CHRONIC VERTEBRAL LOW BACK PAIN
}

\author{
Antonija Hrkac, Lejla Obradovic - Salcin, Vesna Miljanovic - Damjanovic \\ Faculty of Health Studies Mostar
}

\begin{abstract}
INTRODUCTION: Physical therapy in the treatment of chronic low back pain is an essential part of treatment. Apply various methods of physical therapy, but for now, only kinesitherapy has proven performance. For this reason, in the field of physical training, there have been developments of various concepts and methods for treating diseases of the spine. The effectiveness of these concepts and methods than standard methods of kinesiotherapy still no scientific confirmation. According to the selection of experts, McKenzie concept occupies a leading position in the choice of treatment of low back pain.

OBJECTIVE: To compare the effectiveness of the McKenzie concept and standard physical training on pain reduction in chronic vertebral low back pain and compare which of the two methods is more effective in treating chronic low back pain. SUBJECTS AND METHODS: Included were 72 patients, from 30. to 50. age with chronic vertebral low back pain who were treated at the Department of Physical Medicine and Rehabilitation Hospital Mostar. The main measure of research is pain, as measured by VAS scale. The study involved subjects who were at the first measurement had grade 6 on the VAS scale. The subjects were divided into treatment group and control group, which varied according to the method applied in the treatment of physical training. The evaluation was carried out immediately before treatment and after treatment, which lasted 14 days.

RESULTS: The groups had the 36 respondents. Female $s$ was frequent in both groups.

At the start of the study groups did not differ by age, sex and level of pain. After 14 days of repeated pain assessment in both groups. The improvement in the assessment of pain was statistically significant in the control group where the implemented standard kinesitherapy $(z=-3.197 ; p=0,0014)$ and the test group in which the concept is implemented McKenzie $(z$ $=-4.007 ; \mathrm{p}=0.0001)$. There were no statistically significant differences between groups in the reduction of pain $(\mathrm{t}=1.54$; $\mathrm{p}=0,063)$.
\end{abstract}

CONCLUSION: McKenzie and standard practice in kinesitherapy are effective in reduce pain in a short period of treatment. McKenzie concept is not more effective than standard kinesitherapy training on the reduction of pain in chronic vertebral low back pain.

Keywords: low back pain, chronic, kinetic therapy, McKenzie

Correspondence:

Antonija Hrkać

antonija.hr@gmail.com 